\title{
Increase of fire resistance of coating wood with adding mineral fillers
}

\author{
Yuriy Tsapko ${ }^{1,2 *}$, Volodymyr Kyrycyok ${ }^{1}$, Aleksii Tsapko ${ }^{2}$, Olga Bondarenko ${ }^{1}$, and Sergii \\ Guzii $^{1}$ \\ ${ }^{1}$ Kyiv National University of construction and Architecture, Scientific research Institute for binders \\ and materials named after V. Glukhovskii, Povitroflotsky Avenue 31, 03037, Kiyv, Ukraine \\ ${ }^{2}$ National University of Life and Environmental Sciences of Ukraine, Heroes of Defense st. 15, \\ 03041, Kiyv, Ukraine
}

\begin{abstract}
The article covers all the stages of the process of fire protection: as the separation of gases, heat transfer, the swelling of the coating, which is formed during by the action of fire. To determine the fire protection efficiency in the coatings developed, studies have been carried out on determining the combustibility of wood in terms of mass loss and increase in the temperature of flue gases, and it has been established that mass loss of coated wood does not exceed $3 \%$ and the temperature does not exceed $160^{\circ} \mathrm{C}$. The results of the determination of the protection efficiency for the system have shown that under the influence of the hightemperature flame of burning of the material and the loss of the mass of the coating is reduced due to the formation of high-temperature compounds, while the time to reach the limiting temperature increases. Studies on determining the quality of fire protection wood treatment by coating showed that the rate of cooking for a rough sample of wood was more than $2 \mathrm{~mm} / \mathrm{min}$, for fire-proof samples - did not exceed $0.5 \mathrm{~mm} / \mathrm{min}$, which makes it possible to conclude that it is advisable to use them.
\end{abstract}

\section{Introduction}

Since cellulosic materials and products (wood, plywood, paper and fiber materials, and others) are the main conductors of flame propagation, they require adequate protection. Therefore, fire safety is placing increasingly high demands on the effectiveness of fire protection means, as well as on the quality of fire protection materials.

The main requirements for fire protection of cellulose-containing materials are to provide them with the ability to withstand the effects of fire and not to spread the flames on the surface. The change in the decomposition of the material during fire protection is directed toward the formation of non-combustible gases and heavy-duty coke overshoot, as well as inhibition of oxidation in the gas and condensed phase. Fire protection of coatings based on organic binders is effective under the condition of their operation without the action of water and ultraviolet radiation. Therefore, the creation of organo-mineral coatings is a topical issue of creating a modern fire protection of building structures.

\footnotetext{
* Corresponding author: juriyts@ukr.net
} 


\section{Analysis of recent research and publications}

The peculiarity of fire protection of building structures is to create on the surface elements of constructions of heat-insulating, which withstand high temperatures and direct effect of fire. Their presence allows to slow heating of material and keep functions of construction at a fire during the set period of time and makes wood hard burning materials [1].

Modern methods of fire protection of building structures are based on the use of expanding coatings, which are complex systems of organic and inorganic components. But with prolonged action of the flame, they are capable of gradually burning and, accordingly, reducing the fire-resistance of the structure, which requires the addition of mineral fibers capable of forming a more stable foam coke layer [2].

In the recent years, from the proposed direction of research, works are being known to the synthesis of coatings using organic lacquers, refractory oxides and silicates, which in the process of heating form thermo- and heat-resistant ceramic phases [3]. The most common enamel and glass-crystalline coatings [4-6], however, can not provide reliable protection of constructions at temperatures above $1000^{\circ} \mathrm{C}$, since the higher temperatures of exploitation results in the destruction of the organic component, and the inflicted coating becomes porous, which greatly impairs its operational properties.

The influence of inorganic fillers on the flame retardant coating has shown its effectiveness, however, which coating work is not specified and no changes in heat conductivity are observed during the transition of coatings to coke [7-9]. The authors showed only an analytical model for calculating the thermal conductivity of the protective layer of foam coke during the coating process, which takes into account the forms of the pore, but which transformations in the material occur at combustion temperatures is unknown.

Therefore, the installation of the influence of the components included in them on the thermal conductivity and the integrated determination of the effectiveness of fire protection is an unresolved component of ensuring the fire resistance of building structures. This led to the need for research in this direction.

\section{Determine the purpose and objectives of the study}

The conducted researches were aimed at determining the features of fire protection of structures from the effect of high temperature when added to the coating of mineral fillers.

To achieve the goal, the following tasks were solved:

- to determine the features of combustion of of wood with a protective coating on the basis of organo-mineral substances;

- to establish the efficiency of application of mineral fillers of coatings after the thermal action of combustible mixtures, which are characterized by high-temperature effect.

\section{Materials and methods of research}

Experimental samples of wood coatings were prepared on the basis of an organo-inorganic system containing $18 \div 20 \%$ PFA, $12 \div 14 \%$ melamine, $10 \div 12 \% \mathrm{PE}$ and astringent, consisting of $16 \%$ PVA dispersion and water. For the coating of wood, the given organo-inorganic mass was mixed, filled with fillers (minerals - aluminosilicate microspheres, perlite, basaltic scales, metallurgical sludge, ash) in the amount of $10 \%$ and applied to wooden samples made from wood of pine wood thickness of $30 \mathrm{~mm}$ average size of $150 \times 60 \mathrm{~mm}$.

For investigations of the effectiveness of fire protection under the influence of hightemperature flame during combustion of metal, model samples of wooden structures made 
of wood with a thickness of $19 \mathrm{~mm}$, average size of $190 \times 155 \mathrm{~mm}$ and a height of $140 \mathrm{~mm}$, were used, and treated with coatings.

The study on determining the combustibility group of wood treated with the proposed coating was carried out in accordance with the current normative base. The essence of the test method for the experimental determination of the group of heavy and combustible solids and materials according to the influence of the sample is located in the ceramic tube of the OTM installation, the flame of the burner with the given parameters (the temperature of the gaseous combustion products at the exit from the ceramic tube is $200 \mathrm{oC} \pm 5 \mathrm{oC}$ ) In the course of experimental studies, the maximum increase in the temperature of the gaseous combustion products $(\Delta \mathrm{t})$ and the sample mass loss $(\Delta \mathrm{m})$ are recorded. According to test results, materials are classified as:

- heavyweight $-\Delta t<60^{\circ} \mathrm{C}$ and $\Delta m<60 \%$;

- combustible $-\Delta t \geq 60^{\circ} \mathrm{C}$ or $\Delta m \geq 60 \%$.

Determination of fire-fighting efficiency of wood during field tests was carried out using a working methodology, the essence of which was to experimentally determine the effectiveness of fire protection of a building structure made of wood and treated with protective means in the effect of a sample of magnesium flame (model solid ignition) with specified parameters and registration mass loss and degree of charring of the sample after the test.

\section{The main part of the study}

The results of studies to determine the mass loss of samples $(\Delta \mathrm{m}, \%)$ and the increase in the maximum temperature of gaseous combustion products $\left(\Delta t,{ }^{\circ} \mathrm{C}\right)$ of samples of fire retardant wood carried out in laboratory conditions are shown in Fig. 1, 2.

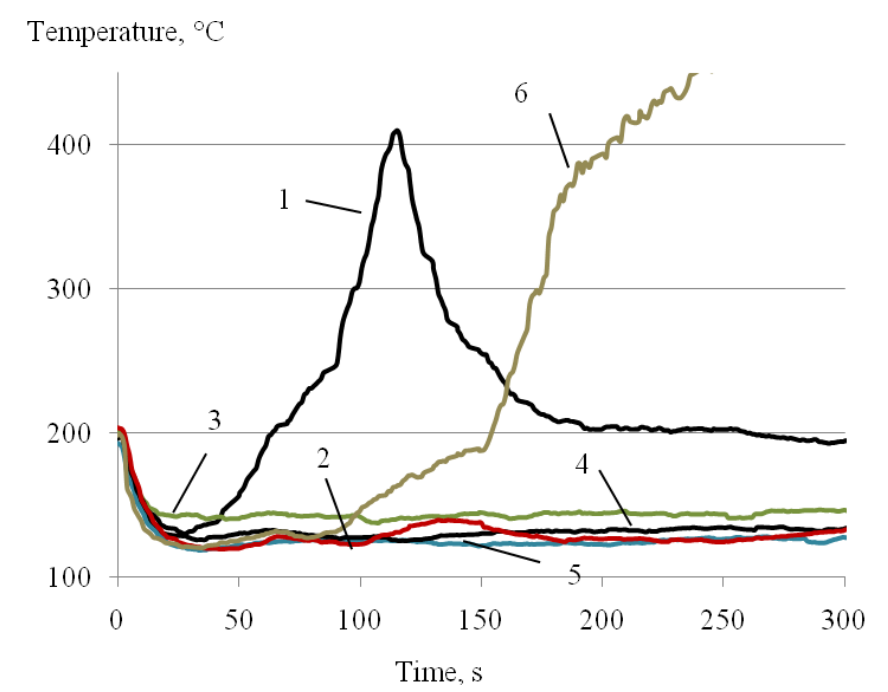

Fig. 1. Dynamics of increase of temperature of flue gases in tests of fire-proof wood on an organic basis (1) with the addition of: 2 - aluminosilicate microspheres; 3 - perlite; 4 - basalt scales; 5 ash; 6 - metallurgical sludge. 


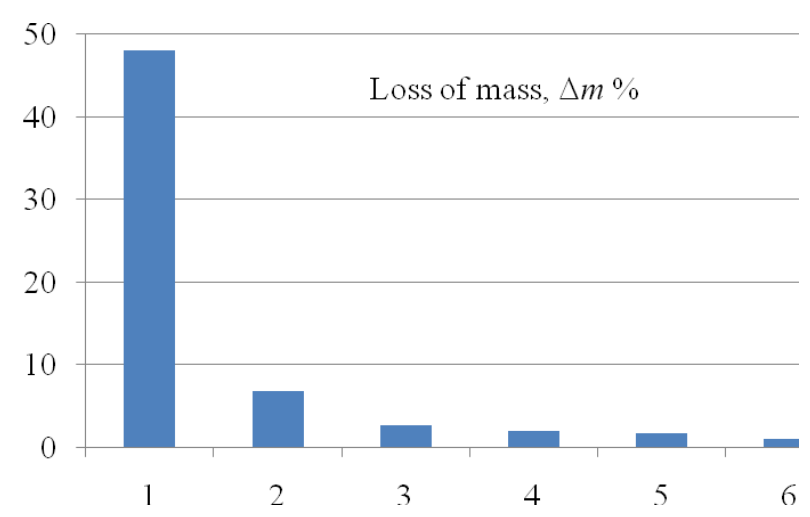

Fig. 2. Results of mass loss of samples Dm,\% of fireproof wood with organic coating, with addition: 1 - untilled; 2 - metallurgical sludge; 3 - perlite; 4 - basalt scales; 5 - ash; 6 - aluminosilicate microspheres.

Studies have shown that rough wood is a combustible material, fire-retardant wood that has been treated with an organic coating with the addition of aluminosilicate microspheres, perlite, basaltic scales, and ash has withstood the temperature effect and relates to heavy materials on the basis of weight loss and flue gas temperature rise. However, the addition to the coating of metallurgical sludge initially countered the thermal effects, but over the years led to an increase in temperature and, consequently, greater loss of sample mass.

Therefore, to determine the effectiveness of fire protection under the influence of mineral fillers on the coating, under the action of a higher temperature, conducted appropriate physical tests.

Table 1 shows the results of mass loss and combustion time of the model center of the wooden construction, Table 2 wood charcoal depth.

Table 1. Results of tests of wooden construction.

\begin{tabular}{|l|c|c|c|c|c|}
\hline \multirow{2}{*}{\begin{tabular}{c}
\multirow{2}{*}{$\begin{array}{c}\text { Protective } \\
\text { coating with }\end{array}$} \\
\cline { 2 - 3 }
\end{tabular}} & \multicolumn{2}{|c|}{ Sample weight, $\mathrm{kg}$} & \multirow{2}{*}{$\begin{array}{c}\text { Burning } \\
\text { time of } \\
\text { Tample, } \mathrm{s}\end{array}$} & $\begin{array}{c}\text { Area of } \\
\text { sample } \\
\text { damage } S, \\
\mathrm{~m}^{2}\end{array}$ & $\begin{array}{c}\text { Speed of } \\
\text { burning down of } \\
\text { standard } v, \\
\mathrm{~kg} /\left(\mathrm{m}^{2} \cdot \mathrm{s}\right)\end{array}$ \\
\hline untilled & 1.620 & 0.972 & 1301 & 0.0342 & 0.0145 \\
\hline $\begin{array}{l}\text { aluminosilicate } \\
\text { microspheres }\end{array}$ & 1.874 & 1.785 & 567 & 0.0340 & 0.0046 \\
\hline perlite & 1.861 & 1.754 & 783 & 0.0342 & 0.0040 \\
\hline basalt scales & 1.569 & 1.498 & 447 & 0.0341 & 0.0047 \\
\hline ash & 1.761 & 1.671 & 552 & 0.0342 & 0.0048 \\
\hline $\begin{array}{l}\text { metallurgical } \\
\text { sludge }\end{array}$ & 1.621 & 1.439 & 501 & 0.0342 & 0.0106 \\
\hline
\end{tabular}

During the tests of combustion of magnesium shavings the formation of a slag layer on the surface of the material was established under which the process of thermal decomposition of wood continued and depending on the properties of the coating, its suspension was carried out in different ways and affected the depth of carbonation. The depth of roasting of rough wood reached $16 \div 20 \mathrm{~mm}$. For a model sample treated with a protective coating with the addition of mineral substances. the outline of the protective coating was observed during the interaction with the flame and there was charcoal of the wood under the coating layer at a depth of only $5 \div 6 \mathrm{~mm}$, respectively. 
Table 2. Results of tests of wooden construction.

\begin{tabular}{|l|c|c|c|}
\hline $\begin{array}{c}\text { Protective coating } \\
\text { with addition }\end{array}$ & $\begin{array}{c}\text { Depth of } \\
\text { charring. } \\
\mathrm{mm}\end{array}$ & $\begin{array}{c}\text { Speed of charring. } \\
\mathrm{mm} / \mathrm{min}\end{array}$ & $\begin{array}{c}\text { The time of the flame of } \\
\text { magnesium on the surface of } \\
\text { the material } t \text {. min }\end{array}$ \\
\hline untilled & $16 \div 20$ & 1.93 & 20.63999 \\
\hline $\begin{array}{l}\text { aluminosilicate } \\
\text { microspheres }\end{array}$ & $4 \div 5$ & 0.61 & 9.019946 \\
\hline perlite & $5 \div 5.2$ & 0.53 & 13.66021 \\
\hline basalt scales & $3 \div 4$ & 0.62 & 7.530295 \\
\hline ash & $5.5 \div 6.0$ & 0.64 & 9.937369 \\
\hline $\begin{array}{l}\text { metallurgical } \\
\text { sludge }\end{array}$ & 1.41 & 6.097788 \\
\hline
\end{tabular}

So the time of exposure of the surface of fire-proof wood to magnesium flame can be estimated if its charcoal depth is known by the equation $[10,11]$ :

$$
t=\frac{x_{e}^{1,23}}{c}
$$

where $\mathrm{t}$ - time of fire influence, min;

$c$ - charcoal speed, $\mathrm{mm} / \mathrm{min}$;

$x_{e}$ - charcoal depth, $\mathrm{mm}$.

The prediction of the average rate of charcoal was carried out according to the dependence:

$$
c=\frac{v}{\rho_{w}},
$$

where $\mathrm{m}$ - burning rate of wood (speed of mass loss), $\mathrm{kg} /\left(\mathrm{m}^{2} \cdot \mathrm{s}\right)$;

$\rho_{w}$ - density of wood in dry condition (humidity $10 \div 12 \%$ ), $450 \mathrm{~kg} / \mathrm{m}^{3}$.

The rate of loss of mass of timber samples was calculated by the equation:

$$
v=\frac{\Delta m}{\tau \cdot S},
$$

where $\Delta m$ - sample mass loss after testing;

$\tau$ - test time;

$S$ - area of sample damage.

As can be seen from Table 2, the samples is treated with a protective coating with the addition of mineral fillers which leads to the creation of an expanded layer of coke and prevents the influence of high temperature and the rate of charcoal wood, and the addition of metallurgical sludge somewhat reduces resistance to high temperature.

\section{Conclusions from research and prospects. further development in this direction}

These studies have established the effectiveness of mixtures of organo-mineral mixtures as fire retardant coatings for wood. in particular:

- in the case of the effect of heat from standard burner burning on samples of treated coatings on the basis of organo-mineral mixtures. the weight loss and the temperature of flue gases did not exceed the specified value. however. a protective layer which has a 
substantial thickness to the building structure to ensure its protection should be used. but the case of a sample treated with a coating on the basis of organic-mineral compounds. the fire resistance of wood is significantly increased due to the formation of a coke layer with minimal consumption of coating;

- full-scale tests using model designs of wooden construction constructions under the influence of high-temperature flames have shown that coatings based on mixtures with the addition of minerals can withstand high temperatures. effectively prevent the penetration of heat to the material due to the formation of expanded layer of coke. which affects the rate and depth of absorption.

Further research will focus on the processes of forming the structure of the protective layer and establishing a connection between the nature of the components and the properties of the coatings. such as the formation of foam coke. as well as resistance to heat and weather.

\section{References}

1. V. Artemenko, Collection of scientific works of LDU BZD. Fire safety, 25, 6-11, (2014)

2. A. Kravchenko, Yu. Tsapko, O. Tsapko, Building materials. products and sanitary equipment NDIBMV, 57, 61-67, (2016)

3. M. Givlyud, O. Bashinsky, S. Vovk, Collection of scientific works of Lviv State University, 18, 40-45, (2011)

4. S. Guzii, R. Hela, V. Kirichok, Advanced Materials Research, 688, 107-112, (2013)

5. B. Ciripi, Y. Wang, B. Rogers, Fire Safety Journal, 81, 74-84, (2016)

6. P. Kryvenko, V. Kyrychok, S. Guzii, Eastern-european Journal of Enterprise Technologies, 5 (83), 40-48, (2016)

7. Yu. Tsapko, A. Tsapko, East European Journal Enterprise Technologies, 5/10 (89), 5560, (2017)

8. O. Bondarenko, S. Guzii, E. Zacharchenko, East European Journal Enterprise Technologies, 6/11 (78), 41-47, (2015)

9. F. Fan, Z. Xia, Q. Li, Z. Li, Progress in Organic Coatings, 76 (5), 844-851, (2013)

10. T. Shnal, Fire resistance and fire protection of wooden structures (Lviv, Lviv Polytechnic, 2006)

11. Yu. Tsapko, A. Tsapko, East European Journal Enterprise Technologies, 3/10(87), 50$55,(2017)$ 